\title{
Desafios na formação inicial do professor de Geografia: reflexões acerca da teoria e da prática
}

\author{
Francisco Otávio Landim Neto* \\ Maria Edivani Silva Barbosa ${ }^{* *}$
}

\section{Resumo}

Este estudo tem por objetivo apresentar algumas reflexões acerca da formação inicial do professor de Geografia, com base nas experiências adquiridas em Estágios Curriculares Supervisionados em Geografia I, II, III e IV. Para tanto, o embasamento metodológico foi fundamentado em trabalhos realizados por estudiosos que pesquisam a temática, com destaque para os temas formação inicial de professores e prática de ensino. Após o estudo, apresentam-se algumas propostas alternativas que visam a contribuir para o ensino-aprendizagem da Geografia escolar.

Palavras-chave: Formação de Professores, Geografia Escolar e Prática de Ensino.

Challenges in the inicial training of teacher of geography: reflections about the theory and the practice

\begin{abstract}
This study aims to present some reflections about the initial formation of a professor of Geography, based on experiences acquired in "Estágios Curriculares Supervisionados em Geografia

* Mestrando em Geografia pelo Programa de Pós-graduação em Geografia da Universidade Federal do Ceará (otaviogeo@oi.com.br).

** Prof ${ }^{\mathrm{a}}$ Ms. Assistente I do Departamento de Geografia da Universidade Federal do Ceará; Doutoranda em Educação Brasileira pelo Programa de Pós-graduação em Educação da Faculdade de Educação da Universidade Federal do Ceará (edivanisb@yahoo.com.br).
\end{abstract}

Geosul, Florianópolis, v. 27, n. 53, p 139-161, jan./jun. 2012 
LANDIN NETO, F.O \& BARBOSA, M.E.S. Desafios na formação inicial...

I, II, III e IV'. Thus, the methodological foundation was based on works done by scholars who research the topic, highlighting the issues "initial teacher education and teaching practice". After the study, it is presented some alternative proposals that seeks to contribute to teaching and learning of geography in school.

Key words: Teacher training, School Geography and Teaching Practice.

\section{Introdução}

O fazer pedagógico não deve ser entendido e praticado pelo professor, como ação neutra e descontextualizada. Há, porém, de ser fundamentada por teorias e práticas comprometidas com a criação e desenvolvimento da emancipação social dos agentes envolvidos no processo de ensino e aprendizagem. Este ensaio objetiva exibir algumas características da formação inicial do professor de Geografia, como também enfocar os saberes necessários à prática docente, considerando-se as possibilidades e os limites impostos ao professor na sociedade atual. São também apresentadas propostas alternativas significativas que visam contribuir para o ensino-aprendizagem geográfico.

$\mathrm{Na}$ tessitura da ação metodológica, foram realizadas leituras de escritos elaborados por estudiosos acerca do assunto ora examinado. A base empírica é marcada por reflexões adquiridas pelas experiências realizadas nos Estágios Curriculares Supervisionados em Geografia I, II, III e IV, oportunizadas pela aproximação com a escola mediante as atividades de observação, participação e regência, de tal sorte que muitas dessas inquietações aqui externadas vieram à tona.

Como forma de problematizar o ensino e a formação inicial do professor de Geografia, alguns questionamentos foram basilares, dentre os quais se destacam: por que os estudantes dos cursos de licenciatura repetiam e/ou repetem a noção de que a Geografia escolar na teoria é uma coisa e na prática é outra? Será 
LANDIN NETO, F.O \& BARBOSA, M.E.S. Desafios na formação inicial...

que existe uma separação de quem escreve a teoria para a escola e de quem a pratica na escola? Quais os saberes necessários à prática docente? Que metodologias podem favorecer o estabelecimento de um ensino Geográfico significativo?

Este texto é constituído por quatro etapas intercomplementares. Na primeira, denominada $A$ formação inicial em licenciatura em Geografia - algumas reflexões, são tecidas considerações acerca das características da formação inicial do professor de Geografia. A segunda, que se intitula Saberes necessários à prática docente, traz proposições concernentes aos conhecimentos teóricos e práticos que a formação inicial do professor de Geografia deve proporcionar a esse profissional. Na seguinte, Propostas alternativas para o estabelecimento de um ensino-aprendizagem significativo da Geografia Escolar propõe-se o uso de recursos didáticos, como os textos de circulação social, as linguagens cartográfica, gráfica e da codificação cinematográfica. Com a apropriação destes recursos de ensino por parte dos professores e alunos, o ensino e a aprendizagem geográfica terão maior significado nas vidas dessas pessoas influenciado sobremaneira o ambiente educacional onde se encontram. $\mathrm{Na}$ última etapa, aduzem-se as Considerações Finais.

\section{A formação inicial em Licenciatura em Geografia - algumas reflexões}

É comum se ouvir dos graduandos do curso de Geografia da Universidade Federal do Ceará - UFC certas afirmações negativas, referentes ao ensino de Geografia. São chavões recorrentes no discurso de professores e alunos que envolvem desconfianças, pessimismos e análises sobre o objetivo da Geografia escolar; extensões também repetidas nos corredores da Universidade e em outros espaços de socialização.

As palavras pessimistas sobre a Geografia escolar são repetidas nos corredores da Universidade por colegas de sala ou desconhecidos, porém, estudantes: “a Geografia é uma disciplina 
LANDIN NETO, F.O \& BARBOSA, M.E.S. Desafios na formação inicial...

enfadonha, simplória e decorativa"; "a Geografia é uma matéria mnemônica, cansativa, sem criatividade e que sempre leva os estudantes a adormecerem, quando se sentem chateados por não encontrarem o sentido em permanecer dentro de uma sala de aula estudando sobre relevo, clima, solo, geologia, astronomia, cidade, campo, população, calotas polares, indústria, etc". Afora isso, a murmuração recai sobre os nomes complicados que são necessários memorizar e o uso dos números para apresentação desses conteúdos".

Dos concludentes do curso de graduação em Geografia, constantemente, se ouviam segundas frases que já envolviam a superação, somente pela academia, daquelas alocuções há pouco mencionadas a sua não possibilidade de realização na escola. Foi quase "natural", ouvir desses alunos a afirmação de que "na teoria a Geografia escolar é uma coisa e na prática é outra". Com efeito, Luckesi (2010, p. 32 e 33) é enfático em analisar que tal

[...] separação entre teoria e prática, entre o "que fazer" e o "como fazer", conduz a distorções, creio eu, mais complexas na prática educacional, quando caminhamos para as especializações do setor educacional, onde estão presentes os profissionais que planejam e, contudo, não executam nem avaliam; profissionais que executam, sem ter planejado e que não vão avaliar; profissionais que vão avaliar, sem ter planejado e executado (...) este esfacelamento entre teoria e prática é interessante aos detentores do poder, pois que sempre poderão tomar as decisões fundamentais deixando aos executores tão somente as decisões de "como fazer" sem nunca lhes permitir interferência no "o que fazer".

Quase natural se afigurava escutar daqueles que já exercem o magistério a seguinte asserção: "vocês vão ver que tudo isso aí que está no papel bonitinho, na prática, vai se desmanchar". E ainda mais, "a Geografia crítica na escola é uma ficção; o negócio por lá é cumprir a burocracia e os horários de aula, pois o conteúdo é o menos discutido". 
LANDIN NETO, F.O \& BARBOSA, M.E.S. Desafios na formação inicial...

Estas observações reforçam o que Kaercher (2004) indaga “A Geografia crítica na escola era um pastel de vento?". Deve-se ter a clareza de que a Ciência geográfica constitui ramo cientifico social e, ao ser estudado, tem que considerar o aluno e a sociedade de que é partícipe. Não pode ser uma coisa alheia, distante, desligada e desconectada da realidade, um amontoado de assuntos ou temas soltos e/ou fragmentados, sempre defasados ou de difícil compreensão pelos estudantes. Ela não pode ser feita apenas de descrições de lugares distantes ou de fragmentos do espaço. No magistério de Callai (2001, p.58).

A geografia que o aluno estuda deve permitir que o aluno se perceba como participante do espaço que estuda, onde fenômenos que ali ocorrem são resultados da vida e do trabalho dos homens e estão inseridos num processo de desenvolvimento (...) $\mathrm{O}$ aluno deve estar dentro daquilo que está estudando e não fora, deslocado e ausente daquele espaço, como é a geografia que ainda é muito ensinada na escola: uma geografia que trata o homem como um fato a mais na paisagem, e não como um ser social e histórico.

Se o estudante for visto como um ser neutro, sem vida, sem cultura, nem história, um ser que não trabalha, tampouco produz riqueza, entidade alheia ao momento histórico e aos espaços geográficos determinados, "a verdade geográfica do indivíduo (aluno) se perde, e a geografia torna-se alheia a ele" (RESENDE, 1989). Isso implica uma qualidade de ensino que deixa muito a desejar. A Geografia que se ensina e se aprende não motiva mais o aluno e sim o distancia das suas reais necessidades.

Cabe ressaltar a importância da formação inicial do professor de Geografia como agente educacional, que propicia diversas elaborações e reelaborações dos saberes geográficos no ensino básico. Entende-se que prática e teoria, na atividade professoral jamais se separam. O que pode haver é uma polarização de competências, pois conforme ensina Brandão (2010.p.56), ocorre pela divisão entre "os que se situam 
LANDIN NETO, F.O \& BARBOSA, M.E.S. Desafios na formação inicial... preponderantemente do lado do fazer (professores e técnicos nas escolas) e os que se situam preponderantemente do lado de pensar (pesquisadores e cientistas em universidades)". Se isso for verdade, o que passa a existir agora são práticas docentes diferenciadas dentro da escola, exercícios que bebem de teorias diversas (individuais, estatais, neoliberais e crítico-radicais); ou há os que chegam até a se embriagar com teorias (do uso do livro didático como o que encaminha a aula), sem saber que as usam enquanto tais.

No que tange ao ensino de Geografia, bem como dos demais componentes curriculares, torna-se necessário considerar a análise e a crítica que se faz atualmente à instituição escola e aos cursos de formação de professores de Geografia, situando-os no contexto político, social e econômico do mundo, em especial do Brasil. Tanto a escola como a disciplina e o professor de Geografia devem ser considerados no âmbito da sua sociedade comum. Essa contextualização se integra ao objeto da ciência, à dinâmica apresentada pela disciplina na escola e à questão pedagógica, que envolve necessariamente a conjunção de problemas do objeto, da ciência e do método.

Embora se queira "avançar" no nível das discussões acadêmicas, muitas coisas parecem estar resolvidas, a prática da sala de aula é ainda hoje assim, deveras fragmentada em itens sem sentido, isolados, e, no conjunto, sem o encadeamento que the permita ter significado. Esse fracionamento dos conteúdos é reflexo direto da formação acadêmica em que há docentes e estudantes fechados em seus mundos geográficos, sendo a especialização dos conhecimentos já incentivada desde o início do curso de graduação. No mesmo caminho desta ideia, Vesentini entende com lucidez, que

Formar especialistas é uma atribuição dos cursos de pósgraduação (ou de especialização) e não da graduação. E o geógrafo (professor ou não, pois essa diferença no fundo é ou deveria ser pouco importante) deve ter uma formação completa na sua área, estando apto a dar aulas no ensino 
LANDIN NETO, F.O \& BARBOSA, M.E.S. Desafios na formação inicial...

elementar ao ensino médio, e a exercer outras atividades nas quais a sua presença costuma ser requisitada: análise ambiental, turismo, planejamentos etc. (2009. p. 239).

Convém enfatizar a noção de que a formação do professor constitui elemento primordial para a constituição e reformulação dos conhecimentos geográficos fundamentais e de seus significados sociais. Na lição de Marinho (2006, p. 354), “a mudança na universidade pública exige uma educação com formação efetiva, na formação de um pensamento que interrogue, reflita e critique e que eleve ao plano dos conceitos os problemas postos como dados e insuperáveis". Para tanto, não basta ao professor possuir domínio da matéria (conteúdos), mas é fundamental que ele possua a capacidade de pensar criticamente, desvendar os fenômenos que permeiam a realidade social e que se imponha como sujeito transformador desta realidade.

\section{Saberes necessários à prática docente}

Quando se discute a temática os saberes docentes e a formação inicial de professores, é necessário comentar a respeito dos seguintes pontos: a prática docente, o processo ensinoaprendizagem e a relação teoria-prática no cotidiano escolar. Recorre-se, pois, à inteligência de Sampaio $(2008$, p.3) para quem

São saberes necessários a todos/as os/as professores/as, de qualquer nível ou modalidade, reconhecer e pautar a prática pedagógica nas idéias de que: os alunos são sujeitos de aprendizagem e suas características cognitivas devem ser conhecidas e consideradas; deve-se respeitar e tomar como base os saberes da experiência do aluno, do seu contexto e de sua cultura para a organização do currículo e do planejamento didático; é preciso ter atitude de pesquisador, investigando, problematizando e discutindo coletiva e permanentemente sua prática, encarando-a como fonte de conhecimento e aperfeiçoamento pedagógico; é necessário repensar as formas de mediação dos conteúdos e de avaliação do desenvolvimento do aluno; enfim, de que 
LANDIN NETO, F.O \& BARBOSA, M.E.S. Desafios na formação inicial...

educação é um direito, por isso é papel da escola e de seus profissionais ensinar aos alunos, quem quer que eles sejam. Ter amplos e sólidos conhecimentos sobre o campo da educação como prática social permitirá a todos/as os/as professores/as fundamentar e melhorar sua atuação na área específica em que estiverem trabalhando.

Os professores cada vez mais se deparam com situações desafiadoras em suas práticas do cotidiano, dentre as quais é válido citar: a escola como ambiente educacional cansativo; estudantes desmotivados; deficiência na formação inicial; elevada carga horária de trabalho; e baixos salários, que se podem caracterizar como vergonhosos. Exige-se, todavia cada vez mais do professor, para que este dê conta de um corpo de conhecimentos e saberes fundamentais para a sua atuação educacional.

A fim de se ter a formação do estudante no patamar de Ensino Fundamental e Médio, na perspectiva crítica, torna-se imprescindível repensar a prática docente, colocando o professor como agente mediador das relações entre estudantes e conhecimentos. Para que isso ocorra, é determinante que na sua formação inicial the seja propiciada a oportunidade de bem formular um ponto de vista crítico sobre a organização do espaço geográfico, proporcionando o domínio dos conteúdos a serem ensinados, como também a capacidade de refletir o próprio exercício docente. Com efeito, a expectativa é de que, consoante a óptica de Pontuschka, Paganelli \& Cacete,

Além de dominar conteúdos, é importante que o professor desenvolva a capacidade de utilizá-los como instrumentos para desvendar e compreender a realidade do mundo, dando sentido significativo a aprendizagem. Á medida que os conteúdos deixam de ser fins em si mesmos e passam a ser meios para a interação com a realidade, fornecem ao aluno os instrumentos para que possa construir uma visão articulada, organizada e critica do mundo. (2007.p.97) 
LANDIN NETO, F.O \& BARBOSA, M.E.S. Desafios na formação inicial...

$\mathrm{O}$ trabalho professoral deve ser fundamentado no estabelecimento de condições e situações didáticas que estimulem a curiosidade e a criatividade dos estudantes. De tal maneira, faz-se crucial $o$ argumento de que o docente também seja um pesquisador. Invita-se, novamente, a reflexão de Pontuschka, Paganelli \& Cacete,

A perspectiva de trabalhar de forma investigativa pressupõe uma mudança de atitude perante ao conhecimento. Significa ultrapassar a visão da prática pedagógica como simples transmissão de conhecimento pronto e acabado que os alunos não possuem e implica outra concepção de educação, de acordo com a qual o conhecimento é visto a luz de seu processo de produção e apropriação, como um produto social de contextos históricos determinados revelando-se, portanto, algo provisório, em permanente processo de construção e reconstrução (2007.p.98).

As instituições formadoras de professores precisam oferecer oportunidades aos professores para desenvolver as capacidades básicas de pensamento, permitindo-lhes visualizar as essências para ir para além de saber coisas, mas também receber uma informação e defrontá-la com a realidade. Com suporte nesta constatação, é licito assinalar o fato de que, convidando o magisterial argumento de Paulo Freire,

Não há ensino sem pesquisa e pesquisa sem ensino. Esses que-fazeres se encontram um no corpo do outro. Enquanto ensino continuo buscando, reprocurando. Ensino porque busco, porque indaguei, porque indago e me indago. Pesquiso para constatar, constatando, intervenho, intervido educo e me educo. Pesquiso para conhecer o que ainda não conheço e comunicar ou anunciar a novidade (1996, p.29).

Freire (1996) acredita que um dos maiores desafios do educador em sua práxis consiste em não transformar seus educandos em apenas receptores passivos a espera da absorção dos 
LANDIN NETO, F.O \& BARBOSA, M.E.S. Desafios na formação inicial... conhecimentos transferidos pelo professor. De acordo com esse juízo freireano:

Saber que ensinar não é transferir conhecimento, mas criar as possibilidades para a sua própria produção ou a sua construção. Quando entro em uma sala de aula devo estar sendo um ser aberto a indagações, à curiosidade, às perguntas dos alunos, as suas inibições; um ser crítico e inquiridor, inquieto em face da tarefa que tenho - a de ensinar e não a de transmitir conhecimento (p. 47).

Desta maneira, é fundamental que os professores elaborem e reciclem seus conhecimentos na participação e incentivo aos educandos a reconstituírem seus saberes e ideias sobre distintas realidades, fazendo-os compreender que, adquirindo educação e sabendo discernir o que é certo e o que não é, possam intervir na sociedade; e, não somente isso, mas também possibilitando que eles se façam a sujeitos conscientes de seu papel na qualidade de estudantes e sonhadores de um futuro com boas perspectivas.

O diálogo na ideação proposta por Freire (1996), representa uma via de mão dupla, onde existe interação do educando com o educador, baseada na convivência e no respeito. Dialogar implica aceitação do outro como também o profundo respeito pelas ideias e pensamentos expressos por sujeitos ou grupos.

É na contingência dialógica que se radica que os fundamentos da superação do estado de opressão e desigualdade. Nessa perspectiva, o diálogo constitui ato de criação, afirmação reflexiva sobre o mundo e acerca da realidade concreta; é a demonstração da capacidade humana de entender-se. O exercício do diálogo requer, todavia, de cada sujeito, uma atitude humilde e democrática. A prática educativa proposta por Paulo Freire constitui a problematização, questionamentos e indagação, apontando o diálogo e a horizontalidade como elementos importantes no desenvolvimento do processo educativo, no qual haja participação efetiva entre os sujeitos. Assim, a horizontalidade constituída e reconstituída na práxis pedagógica é caracterizada por 
LANDIN NETO, F.O \& BARBOSA, M.E.S. Desafios na formação inicial...

uma relação entre iguais, respeitando as especificidades e os papeis que os diferentes sujeitos desempenham. Dessa forma, nota-se a ocorrência de um rompimento com a concepção tradicional das relações hierárquicas, ou seja, nas quais aqueles poucos que mandam e muitos que obedecem ou, ao menos, devem obedecer. Sob o ponto de vista apresentado por Luckesi,

[...] Formar o educador, ao meu ver, seria criar condições para que o sujeito se prepare filosófica, cientifica, técnica e afetivamente para o tipo de ação que vai exercer. Para tanto, serão necessárias não só aprendizagens cognitivas sobre os diversos campos dos conhecimentos que auxiliem o desempenho de seu papel, mas - especialmente - o desenvolvimento de uma atitude, dialeticamente crítica, sobre o mundo e sua prática educacional. O educador nunca estará definitivamente 'pronto', formado, pois que a sua preparação, a sua maturação se faz no dia a dia, na mediação teórica sobre a sua prática. A sua constante atualização se fará pela reflexão diurna sobre os dados de sua prática. Os âmbitos de conhecimentos que lhe servem de base não deverão ser facetas estanques e isoladas de tratamento do seu objeto de ação: a educação. Mas serão, sim, formas de ver e compreender, globalmente, na totalidade, o seu objeto de Ação. (2010. p. 29).

A prática educativa expressa de forma horizontal requer maior compromisso e mais responsabilidade de todos os envolvidos, fomentando a oportunidade de elaboração coletiva de aprendizados que vão além da apreensão dos teores, ao proporcionar o exercício de valores democráticos e de relações sociais que estimulem a participação politizada.

Uma educação proposta para a emancipação humana não pode deixar de debater fatores sociais, políticos e econômicos, interferentes por via direta no cotidiano das pessoas. Entender os diversos fatores que se interpõem na realidade das pessoas é fundamental para a compreensão crítica e fundamentada da realidade (GARCIA, 1994). 
LANDIN NETO, F.O \& BARBOSA, M.E.S. Desafios na formação inicial...

É necessário enfatizar que a reflexão, o questionamento e a atitude crítica perante o mundo e os projetos hegemônicos ${ }^{1}$ são fatores integrantes de um processo formativo voltado à emancipação humana. Esses princípios devem orientar as práticas desenvolvidas na perspectiva de uma educação significativa, ensejando uma formação na qual teoria e prática prossigam lado a lado.

Ainda na inteligência de Freire (1996),

A capacidade de penumbrar a realidade, de nos miopizar, de nos ensurdecer que tem a ideologia faz, por exemplo, a muitos de nós, aceitar docilmente o discurso cinicamente fatalista neoliberal que proclama ser o desemprego no mundo uma desgraça (...). Ou que os sonhos morreram e que o válido hoje é o pragmatismo pedagógico, é o treino técnico-científico do educando e não a sua formação de que já não se fala. (...) A capacidade de nos amaciar que tem a ideologia nos faz as vezes mansamente aceitar que a globalização da economia é uma invenção dela mesma, ou de um destino que não poderia se evitar (...) fala-se de globalização da economia como um momento necessário da economia mundial a que, por isso mesmo, não é possível escapar, (1996, p. 143-144).

A elaboração coletiva dos conhecimentos deve ter finalidades e desejos, mesmo que a passos lentos, analisando sempre qual a serventia do que é ensinado e quais exemplos se elegem para conversar com os estudantes, a fim de justificar o que se diz aos estudantes. Daí a necessidade constante de elaborar uma Geografia coerente, a propósito do que Callai (2006, p. 152) expressa:

\footnotetext{
${ }^{1}$ Quando se utiliza a expressão projetos hegemônicos, esta se reporta ao modelo neoliberal que emprega como estratégia governamental a redução de gastos do Estado com as políticas sociais. No que concerne à educação, o modelo neoliberal ataca a escola pública com base em estratégias privatizantes.
} 
LANDIN NETO, F.O \& BARBOSA, M.E.S. Desafios na formação inicial...

[...] formar o espírito geográfico requer o emprego de métodos de ensino, metodologias e técnicas que superem a simples transmissão de informações e que se assentam em alternativas para mobilizar o intelecto do aluno, fazendo com que ele se pergunte e não apenas espere respostas. As perguntas não vêm do nada e devem necessariamente superar o senso comum, para o que se faz necessário criar condições, dando oportunidade deter conhecimentos que considerem tanto as referências teóricas quanto as informações relativas ao mundo geral.

A formação docente deve privilegiar a produção de conhecimentos que contribuam para constituição de profissionais reflexivos, críticos e transformadores. Para tanto,

[...] A formação profissional para o magistério requer, assim, uma sólida formação teórico-prática. Muitas pessoas acreditam que o desempenho satisfatório do professor na sala de aula depende de vocação natural ou somente da experiência pratica, descartando-se a teoria. É verdade que muitos professores manifestam especialmente tendência e gosto pela profissão, assim como se sabe que mais tempo de experiência ajuda no desempenho profissional. Entretanto o domínio das bases teórico-cientificas e técnicas, e sua articulação com as exigências concretas do ensino, permitem maior segurança profissional de modo que o docente ganhe base para pensar sua prática e aprimore sempre mais a qualidade do seu trabalho. (LIBÂNEO, 1994.p.28).

$\mathrm{Na}$ atualidade, a ocorrência das dificuldades está relacionada à maneira como são conduzidas as didáticas e metodologias na realidade escolar. A esse respeito, Kaercher é enfático:

Insisto: os nossos maiores problemas não são de conteúdo, mas sim da falta de clareza, para nós mesmos, professores de Geografia, do papel da nossa ciência. Ou a geografia se torna útil para os "não geógrafos" (nossos alunos em especial), ou ela tende a desaparecer! Ou vai continuar diluída com mera "ocupação" dos alunos com informações diversas. Uma 
LANDIN NETO, F.O \& BARBOSA, M.E.S. Desafios na formação inicial...

espécie de "programa de variedades" que fala todos os lugares e povos diversos e distantes. Só que sem cores e sons. Chatice, portanto (KAERCHER, 2009. p. 230).

De acordo com o contexto exposto, é necessário que o Estado assuma as responsabilidades referentes à formação inicial do professor, como também deve existir uma ação contínua de valorização desse ofício de tal modo, a educação básica transita necessariamente pela valorização. Ao discutir este assunto Tedesco (2008, p.156 e 157) entende ser a educação do nível básico como a

[...] que exige níveis mais elevados de profissionalismo especificamente pedagógico. Ensinar a ler e escrever, por exemplo, implica um conhecimento técnico-profissional muito especifico que aumenta até, quando o docente tem de trabalhar com populações de fracos recursos. Dar prioridade à formação técnico-profissional dos educadores que desempenham tarefas na educação básica é uma necessidade, não só do ponto de vista pedagógico, mas também do ponto de vista social. Para, além disso, a formação básica é obrigatória e universal. Colocar os melhores docentes em tarefas de educação básica deveria ser, portanto, uma das exigências democráticas mais importantes. Para tal, além da formação profissional, será necessário definir os incentivos que traduzam esta prioridade política numa imagem social.

Há necessidade contínua dos professores assumirem o direito de realizar a crítica propositiva que deve ser fundamentada numa reflexão teórica das práticas correntes no cotidiano escolar, o que fomentará a visualização e entendimento da omissão praticada pelo Estado, que deixa de cumprir o seu dever de oferecer educação de qualidade para os estudantes.

\section{Propostas alternativas para o estabelecimento de um ensino-aprendizagem significativo da Geografia escolar}

O ensino de Geografia envolve a articulação de uma série de componentes próprios da disciplina, como, por exemplo, projeto 
LANDIN NETO, F.O \& BARBOSA, M.E.S. Desafios na formação inicial... pedagógico, currículo, conteúdos, objetivos, metodologias, estratégias, recursos, e também aspectos sociais e políticos inseridos nos ambientes escolares. No trato do ensino geográfico, o professor deve sempre respeitar os saberes prévios dos alunos, como também exercer o papel de interpretar e contextualizar os conteúdos estudados. Nessa perspectiva, Perrenoud insiste em dizer que

[...] trabalhar a partir das representações dos alunos não consiste em fazê-las expressarem, para desvalorizá-las imediatamente. O importante é dar-lhes regulamente direitos na aula, interessar-se por elas, tentar compreender suas raízes e sua forma de coerência, não se surpreender se elas surgirem novamente, quando as julgávamos ultrapassadas. Para isso, deve-se abrir um espaço de discussão, não censurar imediatamente as analogias falaciosas, as explicações animistas ou antropomórficas e os raciocínios espontâneos, sob pretextos que levam a conclusões errôneas. (2000.p.28 e 29).

O docente deve estar em constante aprimoramento de sua práxis, devendo procurar "geograficizar" os conteúdos estudados contidos em jornais, revistas, músicas, documentários, telejornais, novelas, pois estes veículos informacionais acessados, encontramse mais presentes no cotidiano dos estudantes. $\mathrm{O}$ aluno contemporâneo não necessariamente precisa estar em sala de aula para aprender Geografia. Com a democratização das informações, proporcionada pela mídia, os alunos aprendem cotidianamente através das informações divulgadas pela internet, televisão, jornais, revistas, letras de música, romances, etc. Portanto, a escola e os professores precisam redefinir os papeis assumidos na sociedade da informação. As tecnologias da informação e comunicação redefinem, com efeito, a prática educativa, de modo que, nesta perspectiva,

[...] as novas tecnologias podem reforçar a contribuição dos trabalhos pedagógicos e didáticos contemporâneos, pois, 
LANDIN NETO, F.O \& BARBOSA, M.E.S. Desafios na formação inicial...

permitem que sejam criadas situações de aprendizagem ricas, complexas, diversificadas, por meio de uma divisão do trabalho que não faz mais com que todo o investimento repouse sobre o professor uma que tanto a informação quanto a dimensão interativa são assumidas pelos produtores dos instrumentos (Id.ibid, p. 138).

No que se refere ao papel do professor, este se define pela ajuda ao aluno na reorganização dessas informações; ajudar a selecionar, analisar e interpretar as diversas matérias e perceber quais as ideologias, distorções e imprecisões geográficas são apresentadas nas informações. Deve-se estar em alerta no trato das novas linguagens.

$\mathrm{Na}$ formulação coletiva do ensino e aprendizagem entre professores e alunos, deve-se reconhecer o professor como um agente mediador. A esse respeito, Cavalcanti (2002.p. 18) informa que: "[...] no ensino formal, a atividade do aluno, seu processo intelectual de construção de conhecimentos, é dirigida, não é uma atividade espontânea. É uma atividade mediada, que requer uma intervenção intencional e consciente do professor". Na escolha dessas linguagens, os professores devem considerar que os educandos estão inseridos numa sociedade mergulhada nas tecnologias da informação e comunicação (TICs). Desconsiderar essa realidade é negligenciar os saberes dos estudantes. Nesse sentido, Cavalcanti (2002, p. 85) assegura que

A cultura produzida neste mundo de tecnologias é repleta de informações geográficas. Os filmes, os desenhos, as charges, as fotografias, os slides, os anúncios de publicidade, os CD-ROMs, as músicas, os poemas representam freqüentemente, e das formas mais variadas, o mundos, os fenômenos geográficos, as paisagens.

Diversas linguagens podem transformar o ensino de Geografia mais dinâmico e interativo, a saber: a linguagem gráfica (gráficos, tabelas, croquis); a linguagem cinematográfica; a linguagem cartográfica. Pode-se utilizar ainda outros recursos, 
LANDIN NETO, F.O \& BARBOSA, M.E.S. Desafios na formação inicial... como, por exemplo, os jogos pedagógicos, as gravuras, fotografias e telas. Os trabalhos de campo também são empregados para realizar a leitura e interpretação da paisagem de forma direta. São exemplos as excursões, visitas técnicas e aula de campo. A aplicação adequada dessas metodologias e recursos favorece melhor compreensão dos conteúdos geográficos.

O professor deve trazer para a aula situações cotidianas, para que os estudantes possam observar, coletar dados concretos do espaço vivido e elaborar gráficos. A esse respeito, Passini (2009. p.209) assinala que: "Essa linguagem [gráficos] é importante para os cidadãos do mundo, por que é universal; expõe a essência da informação; desenvolve o pensamento lógico; uma importante ferramenta para investigação e apresentação de resultados de uma pesquisa". Os gráficos permitem a representação de dados em diversos conteúdos, ampliam a importância de tais sistemas de representação, sobretudo porque o gráfico não representa apenas uma linguagem matemática; permitem o tratamento de várias informações de outras áreas do conhecimento. No que tange à utilização dos gráficos em sala de aula,

Nós devemos ensinar o gráfico como uma linguagem visual e tão importante quanto a linguagem escrita, para comunicar ou obter informações. Consideramos a importância de reconhecer o gráfico como linguagem que comunica as informações, com organização lógica, por meio da imagem. (PASSINI 2009, p.214).

Os gráficos são instrumentos didáticos valiosos na compreensão dos conteúdos, visto que os construtores dos gráficos elaboram uma imagem do que está sendo estudado. Outra proposta a ser apresentada diz respeito ao uso da linguagem cinematográfica no ensino de Geografia, sendo que se deve:

Dar ênfase a questões eminentemente geográficas e educacionais, baseando-se em um certo método de análise: um retrospecto do filme e análise de alguns aspectos e conceitos concernentes a geografia, à pesquisa e à 
LANDIN NETO, F.O \& BARBOSA, M.E.S. Desafios na formação inicial...

educação. A ideia é explorar em cada um dos filmes, como maior ênfase, um desses aspectos. O professor, junto com os alunos, poderá selecionar filmes compatíveis com a programação da disciplina escolar. (PONTUSCHKA, PAGANELLI \& CACETE, 2007, p. 265).

A escolha do filme deve ser uma preocupação no momento do planejamento, considerado como um elemento a ser levado em conta pelo professor, que precisa conhecer minimamente esta linguagem do cinema - correspondente à integração de múltiplas linguagens (expressão oral e corporal; a cor, tendo como um plano de fundo a música). Poder-se-ía, no entanto, perguntar: qual é a importância dos filmes? Pontuschka, Paganelli \& Cacete (2007, p. 280) respondem: "o filme tem importância porque pode servir de mediação para o desenvolvimento das noções de tempo e de espaço na abordagem de problemas sociais, econômicos e políticos". Então, é necessário que esse instrumento didático provoque uma rica discussão entre professores e alunos com o intuito da percepção inicial e compreensão das questões e até mesmo conflitos geográficos presentes nas películas.

O trabalho com a cartografia no ensino básico deve dar possibilidades para professores e alunos exprimirem suas representações e contextualizações entre a cartografia e outros conteúdos estudados. A esse respeito, Cavalcanti (2002, p.16) explica que a cartografia

“[...] não é um conteúdo a mais no ensino de Geografia; ele perpassa todos os conteúdos dessa matéria. Os conteúdos de cartografia ajudam a abordar os temas geográficos, os objetos do mundo. Eles ajudam a responder algumas perguntas: 'Onde? Por que nesse lugar?' Ajudam a localizar fenômenos, fatos e acontecimentos estudados e fazer correlações entre eles, são referencias para o raciocínio geográfico.

O professor deve possuir a criatividade da diversificação de suas metodologias de ensino, para, desse modo, fomentar com os 
LANDIN NETO, F.O \& BARBOSA, M.E.S. Desafios na formação inicial... alunos a formulação de um ensino geográfico significativo. Para tanto, o docente pode se utilizar em sua prática textos de circulação social, como jornais, letras de músicas e anúncios de autdoors, entre outros diretamente relacionados com a experiência cotidiana dos estudantes.

$\mathrm{O}$ ensino pode se basear no interesse e na necessidade do aluno. Instigar a dúvida, o questionamento, a partir das experiências sociais dos alunos, é desenvolver a habilidade da leitura, tendo como ponto de partida necessidades de determinada faixa etária. Assim, desperta-se o hábito da leitura sem impor um texto que ainda não seja lido pela aquela faixa etária. $\mathrm{O}$ prazer de ler e fazer perguntas ao texto nasce no aluno que poderá aplicar esse procedimento de leitura a outros textos. Dessa maneira pretendemos desenvolver a leitura sob dois pontos paralelos: um que atenta ao interesse da escola, que é desenvolver intelectualmente o aluno; e outro ao interesse dos alunos, que é ler o que circula no âmbito social (MARCONDES, MENEZES \& TOSHIMITSU 2007.p. 10 e 11).

A importância fundamental na utilização dos textos de circulação social no ensino diz respeito a duas dimensões, a primeira das quais relacionada à acessibilidade destes materiais aos estudantes, enquanto a outra versa sobre o esforço coletivo (professor e dos seus alunos) para interpretar, descobrir, discutir os significados contidos nos textos; e, sobretudo, buscar a percepção de qual e/ou quais são as geografias contidas nos materiais lidos.

Outro instrumento que deve ser levado em consideração no ensino-aprendizagem diz respeito à utilização das mensagens e imagens transmitidas pela televisão, visto que este meio de comunicação de massa é acessado constantemente por crianças e jovens. A ferramenta informacional está constantemente presente no cotidiano dos alunos, portanto, não se pode desprezar a influência da TV na vida dos alunos. Em tal direção, vem Tedesco explicar a noção de que 
LANDIN NETO, F.O \& BARBOSA, M.E.S. Desafios na formação inicial...

[...] A imagem mobiliza, particularmente, as emoções, os sentimentos, a afetividade, enquanto a leitura estimula a racionalidade e a reflexão. As alterações na informação política, por exemplo, são um dos aspectos que se pode apreciar, mais claramente, o impacto da televisão. Para muitos analistas a televisão modificou a natureza da opinião política, que deixou de ser uma opinião baseada na avaliação intelectual das propostas, para se converter numa resposta intuitiva e emocional à apresentação de imagens (2008.p.75).

Nesse âmbito, torna-se necessária a realização constante da crítica, por parte de professores e alunos, aos conteúdos emitidos pela televisão, com o intuito de perceber as contradições e "verdades" propagadas. Com efeito,

[...] alertar os alunos sobre esses aspectos talvez passe a ser também um exercício democrático, pois colocará em evidência o quanto somos presos pelo poder de influência e penetração. Por essa razão, propomos inclusive a Análise de anúncios associados com o público de novelas, um programa que não só atrai, mas também a assiduidade do telespectador é outro ponto gerador de influencia (MARCONDES, MENEZES \& TOSHIMITSU, 2007.p. 27 e 28).

O professor de Geografia deve trabalhar com a aplicação das mensagens transmitidas pela televisão ao ensino, acredita-se que isso enriquecerá a aprendizagem dos alunos. Pode-se pensar, por exemplo, em uma aula cuja temática seja geopolítica e disputa por territórios. O professor poderá trabalhar com documentários, podendo também instruir com os alunos uma interpretação de análises dos discursos veiculados pelos mídia sobre o assunto que está sendo estudado. Dessa forma, existem várias possibilidades de se trabalhar com essas informações, cabendo ao professor apelar para a sua criatividade para optar pela melhor forma de trabalho. 
LANDIN NETO, F.O \& BARBOSA, M.E.S. Desafios na formação inicial...

\section{Considerações finais}

Nesta pesquisa procurou-se teorizar o ensino de Geografia com base na formação inicial do professor e nas práticas adquiridas das experiências dos Estágios Curriculares Supervisionados em Geografia I, II, III e IV. Ao se estabelecer essa relação, constatouse, na prática, uma abordagem marcada pela fragmentação dos conteúdos, característica ainda muito intensa dos cursos de formação de professores. Tal particularidade se traduz na sala de aula da educação básica pelas metodologias e recursos didáticos que denotam um ensino tradicional: o livro didático como definidor dos conteúdos, excessivo uso de aulas expositivas, a fala centrada no professor, a lousa como uso exclusivo para a cópia das tarefas escolares etc.

Com base no que foi observado, comprovou-se o fato de que, apesar das circunstâncias em que o professor se encontra, com salários insatisfatórios, carga horária excessiva, infraestrutura precária das escolas, este pode utilizar-se de meios que ajudam a melhorar a prática de ensino sem muita demanda de tempo e esforço físico. São recursos de fácil aquisição com os quais cotidianamente se tem contato como, por exemplo, os textos de circulação social (jornais escritos, revistas, programas televisivos, etc.), a linguagem cartográfica, cinematográfica e os gráficos. Com a apropriação destes recursos de ensino por parte dos professores e alunos, o ensino e a aprendizagem terão maior significado nas vidas destes sujeitos, que elaboram e reelaboram o ambiente educacional onde se encontram.

\section{Referências bibliográficas}

BRANDÃO, Zaia. Abordagens alternativas para o ensino da didática. In: CANDAU, Vera Maria (org.). A didática em questão. 30. ed. Petrópolis, Rio de Janeiro: Vozes, 2010. p. 55-65.

CALLAI, Helena Copetti. A Geografia e a escola: muda a geografia? Muda o ensino? In: Revista Terra Livre, n. 16. (p. 133-152). São Paulo, 2001. 
LANDIN NETO, F.O \& BARBOSA, M.E.S. Desafios na formação inicial...

CALLAI, Helena C. A articulação teoria-prática na formação do professor de Geografia. In: SILVA, Ainda Maria M. et. al. Educação formal e não formal, processos formativos e saberes pedagógicos: desafios para inclusão social. Encontro Nacional de Didática e Prática de Ensino. Recife: ENDIPE, 2006. p. 143-161.

CAVALCANTI, Lana de Souza. Geografia e praticas de ensino. Goiânia: Alternativa, 2002. 127p.

FREIRE, Paulo. Pedagogia da Autonomia; saberes necessários ás práticas educativa. São Paulo, Paz e Terra, 1996.

GARCIA, Pedro Benjamim. O Pendulo das Ideologias: a educação popular e o desafio da Pós Modernidade. Rio de Janeiro: Relume Dumará, 1994.

KAERCHER, Nestor André. O gato comeu a Geografia Crítica? Alguns obstáculos a superar no ensino-aprendizagem de Geografia. In: PONTUSCHKA, Nídia N. e OLIVEIRA, Ariovaldo U. (orgs.). Geografia em Perspectiva: ensino e pesquisa. São Paulo: Contexto, 2009. p. 221-231.

KAERCHER, Nestor A. "Quando a Geografia Critica pode ser um Pastel de Vento". Mercator - Revista de Geografia da UFC, ano 03, número 06 - Fortaleza, 2004. 60p.

LIBÂNEO, José Carlos. Didática. São Paulo: Cortez, 1994. (Coleção Magistério. Serie formação do professor).

LUCKESI, Cipriano, Carlos. O papel da didática na formação do educador . In: CANDAU, Vera, Maria (org). A didática em questão. 30. ed - Petrópolis, Rio de Janeiro: Vozes, 2010.

MARCONDES, Beatriz; MENEZES, Gilda \& TOSHIMITSU, Thaís. Como usar outras linguagens em sala de aula. 6. ed. - São Paulo: Contexto, 2007.

MARINHO, Cristiane Maria. Universidade e Pós Modernidade. In: RABELO, Jackline \& FELISMINO, Sandra. Cordeiro.(orgs). Trabalho, 
LANDIN NETO, F.O \& BARBOSA, M.E.S. Desafios na formação inicial...

Educação e a Critica Marxista. Fortaleza: Imprensa Universitária da Universidae Federal do Ceará, 2006.

PASSINI, Elsa Yasuko. Gráficos: Fazer e Entender. In: PONTUSCHKA, Nídia N. e OLIVEIRA, Ariovaldo U. (orgs.). Geografia em Perspectiva: ensino e pesquisa. São Paulo: Contexto, 2009. p. 209-215.

PERRENOUD, Philippe. Dez novas competências para ensinar. Tradução Patricia Chittoni Ramos. Porto Alegre: Artmed, 2000. 192p

PONTUSCHKA, Nídia Nacibi. PAGANNELLI, Tamoko Iyda. CACETE, Núria Hanglei. Para Ensinar e Aprender Geografia. São Paulo: Ed Cortez, 2007.

RESENDE, Márcia M. S. O saber do aluno e o ensino de Geografia. In: VESENTINI, José Willian et al (org.). Geografia e Ensino: Textos Críticos. Campinas: Papirus, 1989. p. 83-115.

SAMPAIO, Marisa Narciso. Alguns saberes necessários para Professoras e professores de jovens e adultos. Anped, Grupo de Trabalho a Formação de Professores. Disponível em: www.anped.org.br/reunioes/28/textos/gt08/gt081154int.rtf. Acesso em: 13 de Junho de 2011.

TEDESCO, Juan Carlos. O novo pacto educativo: educação, competitividade e cidadania na sociedade moderna. Tradução José Carlos Eufrásio. Vila Nova de Gaia: Fundação Manuel Leão, 2008.

VESENTINI, Jose Willian. A Formação do Professor de Geografia Algumas Reflexões. In: PONTUSCHKA, Nídia N. e OLIVEIRA, Ariovaldo U. (orgs.). Geografia em Perspectiva: ensino e pesquisa. São Paulo: Contexto, 2009. p. 235-240. 